\title{
Analytical calculation of tube confined concrete elements with strengthened cores
}

\author{
Oleksandr Palyvoda ${ }^{1, *}$, Dmytro Yermolenko ${ }^{2}$, Oleksandr Andriichuk ${ }^{3}$, Mindaugas Vaicekauskas ${ }^{4}$, and Intars Dicmanis ${ }^{5}$ \\ ${ }^{1}$ Kryvyi Rih National University, Department of Industrial, Civil and Urban Construction, 11 Vitalii Matusevysch Str., Kryvyi Rih, \\ 50027, Ukraine \\ ${ }^{2}$ Poltava National Technical Yuriy Kondratyuk University, Department of Highways, Geodesy, Land Management and Rural Buildings, \\ 24 Pershotravnevyj Ave., Poltava, 36011, Ukraine \\ ${ }^{3}$ Lutsk National Technical University, Department of Automobile Roads and Airfields, 75 Lvivska Str., Lutsk, 43018, Ukraine \\ ${ }^{4}$ UAB "Progresyvi Statyba", Neužmirštuolių g. 14, Vilnius, 04124, Lithuania \\ ${ }^{5}$ UAB “MiTek Baltic”, Liepājas iela 34-32, Zemgales priekšpilsēta, Rīga, LV-1002, Latvia
}

\begin{abstract}
The approach to the formation of the analytical method of evaluation of the stress-strain state of complex rod bearing structural elements is considered in the paper. The prerequisites described cover all the fundamental features of deformation of the components in conditions of tube confined concrete with a strengthened core. This is confirmed by the results of our own experimental studies. The case of central axial compression is considered in detail. From the beginning of loading to destruction of a structural element, two fundamentally different stages of work are distinguished: in the beginning - elastic; closer to destruction plastic. The method of variable elasticity parameters is used to describe the performance of concrete in the plastic stage. The mutual influence of components during deformation is revealed by solving the contact problem. The methodology was tested by comparing the results of our own experimental and theoretical results.
\end{abstract}

\section{Introduction}

Every day the world needs more resources conservation, more efficient use of materials and raw materials conservation. The construction industry is one indicator of this. Consider the use of tube confined concrete as one example.

It is known that in compressed tube concrete elements the active force is perceived by both a tube shell and concrete cores $[1,2]$. If in some way to increase the carrying capacity of the core, then it is possible to reduce the cost of steel to obtain a tube confined element with a predetermined bearing capacity [3], which will lead to significant savings in the construction. However, conducting experimental research requires considerable material costs. In such circumstances, it is advisable to attract analytical and numerical research opportunities. Nevertheless, the question of calculating these structures is not straightforward, and there are different views on how to solve them.

The purpose of the presented studies is to formulate the prerequisites for performing the analytical calculation of compressed tube confined concrete elements with a strengthened core, taking into account the previously conducted experimental studies; as well as an assessment of the performance of structural tube confined concrete elements with strengthened cores compared to steel elements.
Analysis of research and publications. Today, buildings and structures that are designed and constructed using tube confined concrete are presented practically all over the world $[4,5]$. At the same time, the question of ambiguity in the calculation of such structures hinders the widespread introduction of this combination of steel and concrete, including taking into account the strengthening of their cores.

Considering a number of advantages that draw attention to the presented structures [5-7], the previously conducted experiments were aimed at clarifying the mechanism of development of the stress strain-state of tube confined concrete elements with a strengthened core for a more accurate and specific evaluation of their characteristics $[7,8]$.

Thus, based on practical experience it is necessary to formulate the prerequisites and construct a general algorithm for the possibility of theoretical evaluation of the stress-strain state of tube confined concrete with strengthened cores.

\section{Results}

The above-mentioned material is based on the experimental studies conducted by the authors earlier [79]. According to the results of these experiments, it was possible to establish the nature of the destruction of the tube confined concrete with strengthened cores of

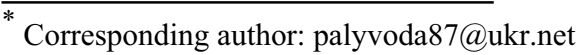


different structural forms, the distribution of deformations at all stages of loading. Based on all this experience, the following prerequisites have been formed for the theoretical evaluation of the stress-strain state of a tube confined concrete with strengthened cores:

- the materials used for the manufacture of tube confined concrete elements, which are isotropic bodies;

- - work under load of steel reinforcing rod and steel shell is presented in the form of Prandtl diagram (Fig. 1);

- work under concrete loading is presented in the form of its own work diagram (Fig. 2);

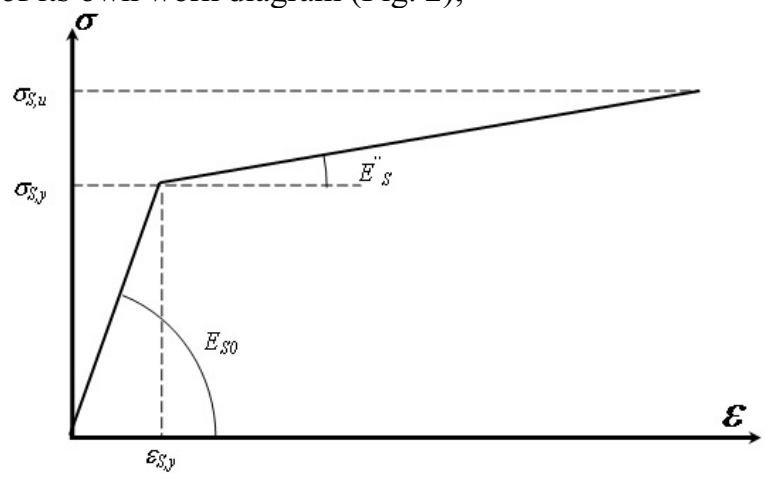

Fig. 1. Dependence of the steel shell deformation module on deformations.

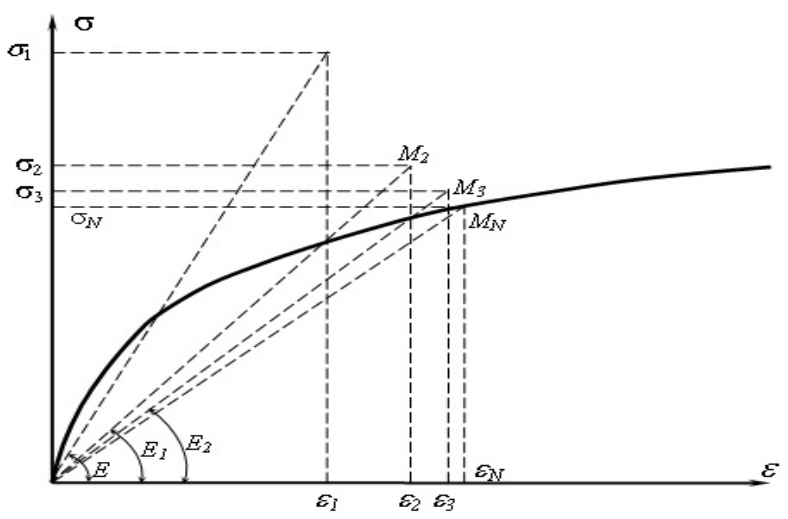

Fig. 2. Dependence of the concrete core deformation module on deformations.

- concrete core, core reinforcement and steel shells work together throughout the loading period;

- in tube confined concrete elements with strengthened cores due to high-strength concrete, the concrete core and the tube-shell work in parallel until the fluidity is reached in the tube-shell and do not affect each other;

- during the whole deformation process the concrete core works with structural and reinforcing steel jointly;

- the materials that make up the tube confined concrete element are considered as isotropic elasticplastic;

- between stresses and strains in the materials of the tube confined concrete element, a linear dependence is assumed upon reaching the first limit state in strength;

- throughout the deformation process, the longitudinal axis of the concrete element remains straight;

- the flat section hypothesis is considered valid;
- the geometric dimensions of the cross-section and the physical properties of the materials along the length of the concrete element do not change;

- we consider tube-shell, concrete core and reinforcement deform jointly;

- static condition remains: the amount of effort on the longitudinal axis is zero;

- the tube shell works in a flat stress state; concrete core - in bulk; additional rod reinforcement - in uniaxial compression.

\subsection{Stage of elastic work of materials}

From the beginning, the work of tube confined concrete elements with strengthened cores under the condition of elastic work of steel and concrete is considered. In the general formulation, the task of evaluating the stressstrain state of tube confined concrete elements with strengthened cores is to find fifteen unknowns: displacement (u, v, w); deformation $\left(e_{\mathrm{x}}, e_{\mathrm{y}}, e_{\mathrm{z}}, \gamma_{\mathrm{xy}}, \gamma_{\mathrm{yz}}, \gamma_{\mathrm{zx}}\right)$; stress $\left(\sigma_{\mathrm{x}}, \sigma_{\mathrm{y}}, \sigma_{\mathrm{z}}, \tau_{\mathrm{xy}}, \tau_{\mathrm{yz}}, \tau_{\mathrm{zx}}\right)$. In this case, a set of such unknowns must be found for each separate component of the tube confined concrete with a strengthened core.

The values of the unknowns must satisfy the equation of continuum mechanics in the area occupied by the experimental element [9]; in particular, the equation of equilibrium equation, and the conditions on the lateral surfaces and on the surfaces of the edges

$$
\begin{gathered}
\frac{\partial \sigma_{x}}{\partial x}+\frac{\partial \tau_{x y}}{\partial y}+\frac{\partial \tau_{x z}}{\partial z}=0 ; \\
\frac{\partial \tau_{y x}}{\partial x}+\frac{\partial \sigma_{y}}{\partial y}+\frac{\partial \tau_{y z}}{\partial z}=0 ; \\
\frac{\partial \tau_{z x}}{\partial x}+\frac{\partial \tau_{z y}}{\partial y}+\frac{\partial \sigma_{z}}{\partial z}=0, \\
\sigma_{x} \cos (n, x)+\tau_{x y} \cos (n, y)=X_{n}=0 ; \quad \tau_{x z}=f_{1} ; \\
\tau_{y x} \cos (n, x)+\sigma_{y} \cos (n, y)=Y_{n}=0 ; \quad \tau_{y z}=f_{2} ; \\
\tau_{z x} \cos (n, x)+\tau_{z y} \cos (n, y)=Z_{n}=0, \quad \sigma_{z}=f_{3},
\end{gathered}
$$

where $f_{1}, f_{2}, f_{3}$ - given functions on the edges with $z=0$ and $z=l$.

The stresses are represented by deformations by Hooke's physical equations:

$$
\begin{aligned}
& \sigma_{x}=\lambda \theta+2 \mu \varepsilon_{x} ; \quad \sigma_{y}=\lambda \theta+2 \mu \varepsilon_{y} ; \quad \sigma_{z}=\lambda \theta+2 \mu \varepsilon_{z} \\
& \tau_{x y}=\mu \gamma_{x y} ; \quad \tau_{y z}=\mu \gamma_{y z} ; \quad \tau_{z x}=\mu \gamma_{z x}, \\
& \text { where } \\
& \theta=\varepsilon_{x}+\varepsilon_{y}+\varepsilon_{z} ; \quad \lambda=E v /[(1+v)(1-2 v)] ; \quad \mu=E /[2(1+v)]
\end{aligned}
$$

Deformations are shown by moving along the equations of Copies:

$$
\begin{aligned}
& \varepsilon_{x}=\frac{\partial u}{\partial x} ; \quad \varepsilon_{x}=\frac{\partial v}{\partial y} ; \quad \varepsilon_{x}=\frac{\partial w}{\partial z} \\
& \gamma_{x y}=\frac{\partial u}{\partial y}+\frac{\partial v}{\partial x} ; \quad \gamma_{y z}=\frac{\partial v}{\partial z}+\frac{\partial w}{\partial y} ; \quad \gamma_{z x}=\frac{\partial w}{\partial x}+\frac{\partial u}{\partial z} .
\end{aligned}
$$




\subsection{Stage of plastic work of materials}

It is experimentally proved that the relationship between the compressive force and the deformation does not retain a linear dependence, when reaching $70-90 \%$ of $N_{1 i}$ and becomes curvilinear. The reason for this is the appearance of plastic deformation. Application of the provisions of the theory of elastic-plastic deformations, as pointed out by A.A. Ilyushin [10], is possible only in conditions of simple loading. That is, when all components of the strain tensor change in proportion to one parameter. Under these conditions, the law of generalized curves works. In any stress state, the diagram $\sigma_{i}-\varepsilon_{i}$ is similar to the diagram $\sigma-\varepsilon$ with uniaxial compression (Fig. 1, Fig. 2). In this case, the elasticity modulus is replaced by the variable module $E^{\prime}$ :

$$
\sigma_{i}=E^{\prime} \cdot \varepsilon_{i},
$$

where $\sigma_{\mathrm{i}}-$ intensity of stress,

$\sigma_{i}=\frac{1}{\sqrt{2}} \sqrt{\left(\sigma_{x}-\sigma_{y}\right)^{2}+\left(\sigma_{y}-\sigma_{z}\right)^{2}+\left(\sigma_{z}-\sigma_{x}\right)^{2}+6\left(\tau_{x y}^{2}-\tau_{y z}^{2}+\tau_{x z}^{2}\right)} ;$

$\varepsilon_{i}-$ intensity of deformations,

$\varepsilon_{i}=\frac{\sqrt{2}}{2(1+\mu)} \sqrt{\left(\varepsilon_{x}-\varepsilon_{y}\right)^{2}+\left(\varepsilon_{y}-\varepsilon_{z}\right)^{2}+\left(\varepsilon_{z}-\varepsilon_{x}\right)^{2}+\frac{3}{2}\left(\gamma_{x y}^{2}+\gamma_{y z}^{2}+\gamma_{x z}^{2}\right)}$; $E^{\prime}=\operatorname{tg} \alpha-$ secant modulus of deformation.

In order to describe the work of steel tube shell and steel reinforcement, the dependence in the form is taken [8]:

$$
\sigma_{i}=E^{\prime}(1-\omega) \cdot \varepsilon_{i}
$$

where $\omega=f\left(\varepsilon_{i}\right),-$ function of intensity of deformations, nonzero only after the appearance of plastic strains.

The diagram of the steel work is presented in the form of two-branch (Fig. 1). The first branch is the zone of elastic deformation and is characterized by a modulus of deformation $E^{\prime}=\operatorname{tg} \alpha=E_{s}$; the second is the zone of strengthening and is characterized by $E^{\prime}=\operatorname{tg} \alpha=E_{s}$. Then

$$
\sigma_{s i}=E_{s 0}\left[1-\lambda\left(1-\frac{\varepsilon_{s y}}{\varepsilon_{s i}}\right)\right] \varepsilon_{s i}
$$

where $\lambda\left(1-\varepsilon_{s y} / \varepsilon_{s i}\right)=\omega ; \lambda=1-E_{s}^{\prime \prime} / E_{s 0}$; $\varepsilon_{s i}=\frac{2}{3} \sqrt{\frac{1-v+v^{2}}{(1-v)^{2}}\left[\varepsilon_{S x}^{2}+\varepsilon_{S z}^{2}+\varepsilon_{S z} \varepsilon_{S x}\left(\frac{3 v}{1-v+v^{2}}-1\right)\right]}$

\subsection{Determination of contact forces}

In the case of transferring the load to the tube confined concrete element through a stamp on a complex section, the proportion of force is distributed between the concrete core and the shell in accordance with the ratio:

$$
P=P_{c}+P_{S}
$$

where $P_{C}$ та $P_{S}$ - the proportion of the external force that is perceived by the separate parts of the cross-section of the tube confined concrete element, namely the concrete and the tube shell.

The intensity of the external load on the top edge:

$$
q_{z}=\frac{P}{A}
$$

where $\mathrm{A}$ - area of the complex section of tube confined concrete element.

External load intensity for separate section elements:

$$
q_{c z}=\frac{P_{c}}{A_{c}}, \quad q_{S z}=\frac{P_{S}}{A_{S}}
$$

The distribution of the external force between the concrete and the steel part remains unknown. Movement of the edge sections of concrete and steel along the $Z$ axis occurs together:

$$
\varepsilon_{c Z}=\varepsilon_{s Z}
$$

where $\varepsilon_{c z}=\frac{\sigma_{c z}}{E_{c}}, \varepsilon_{s z}=\frac{\sigma_{s z}}{E_{s}}, \varepsilon_{c z}=\frac{P_{c}}{A_{c} E_{c}}, \sigma_{s z}=\frac{P_{s}}{A_{s}}$.

Thus

$$
\frac{\sigma_{c Z}}{E_{c}}=\frac{\sigma_{s Z}}{E_{S}},=>\quad \sigma_{s Z}=\sigma_{c z} \frac{E_{S}}{E_{c}}=\sigma_{c z} \cdot n,
$$

where $n=\frac{E_{S}}{E_{c}}$.

To determine the value of the contact force, we used the results reported in [11] D. Weinberg. Fig. 3 shows the geometric part of the problem.

Thus, if the length of the shell and the core are the same size, then the value of the contact pressure is equal to:

$$
p=\frac{\frac{\Delta}{d}}{\frac{1}{E_{1}}\left(\frac{1+k_{1}^{2}}{1-k_{1}^{2}}-\mu_{1}\right)+\frac{1}{E_{2}}\left(\frac{1+k_{2}^{2}}{1-k_{2}^{2}}-\mu_{2}\right)},
$$

where $\Delta-$ the difference of the diameters of the contact surfaces before the joint, sm;

$d$-diameter of the contact surface, sm;

$k_{1}=\frac{d_{1}}{d}-$ the ratio of the diameters of the inner body;

$k_{2}=\frac{d_{2}}{d}-$ the ratio of the diameters of the outer body;

$d_{1}$ - the inner diameter of the inner body;

$d_{2}$ - the outer diameter of the outer body;

$E_{1}, \mu_{1}$ - the deformation modulus and the coefficient of lateral distortion of the inner body;

$E_{2}, \mu_{2}$ - the deformation modulus and the coefficient of lateral distortion of the outer body.

The calculation algorithm includes the following steps:

1. To identify the proportion of force which is distributed between the elements of the cross section of the concrete 
(concrete, steel outer pipe, steel inner pipe, additional reinforcement), depending on the design of the prototype.

2. Evaluate the stress-strain state of the concrete core.

3. Evaluate the stress-strain state of the steel shell.

4. Evaluate the stress-strain state of the additional reinforcement.

5. Calculate the values and sign of the difference between the initial radius of contact surface between the concrete core and the steel tube.

6. Determine the value of the contact pressure between the concrete and the steel tube.

7. Return and carry out items 2-6.

8. Refine the values of the modulus of the materials elasticity and compare with the values at the beginning of the calculation.

9. In the case of differences in the values of the modulus of elasticity by more than $3 \%$, repeat the items $2-8$ with the specified values. Otherwise, proceed to item 10 .

10. Compare the value of longitudinal deformation of a steel tube with a limit value (approximately $200 \times 10^{-5}$ ).

11. Subject to item 10, complete the calculation is and fix the value of the external force and the longitudinal stress in the concrete core. Otherwise, increase the external force by the incremental value $(\Delta N)$ and repeat the calculation according to items 2-10.

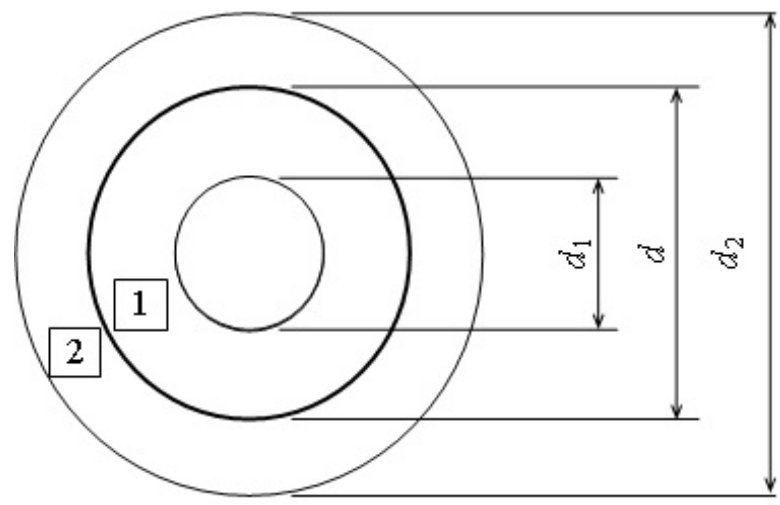

Fig. 3. Scheme before determining the value of the contact force between the elements of the cross-section of the tube confined concrete element.

Fig. 4 shows a block diagram for calculating the carrying capacity of tube confined concrete elements with strengthened cores.

\subsection{Implementation of the methodology}

Implementation of the methodology, including and design circuits of the elements is presented in detail in [8]. During the development of the method for evaluating the stressstrain state of the investigated structures, it was assumed that the tube shell and the concrete core work in parallel until the tube shell fluidity occurs. As experimental studies of tube confined concrete elements with a core of high-strength concrete have shown that by the time when fluidity occurs in the shell, the latter with the concrete core work in parallel. Later the concrete core and shell work together. Feature of deformation of prototypes is symmetry with respect to the central axis. For convenience, the stress-strain state is described with cylindrical coordinates.

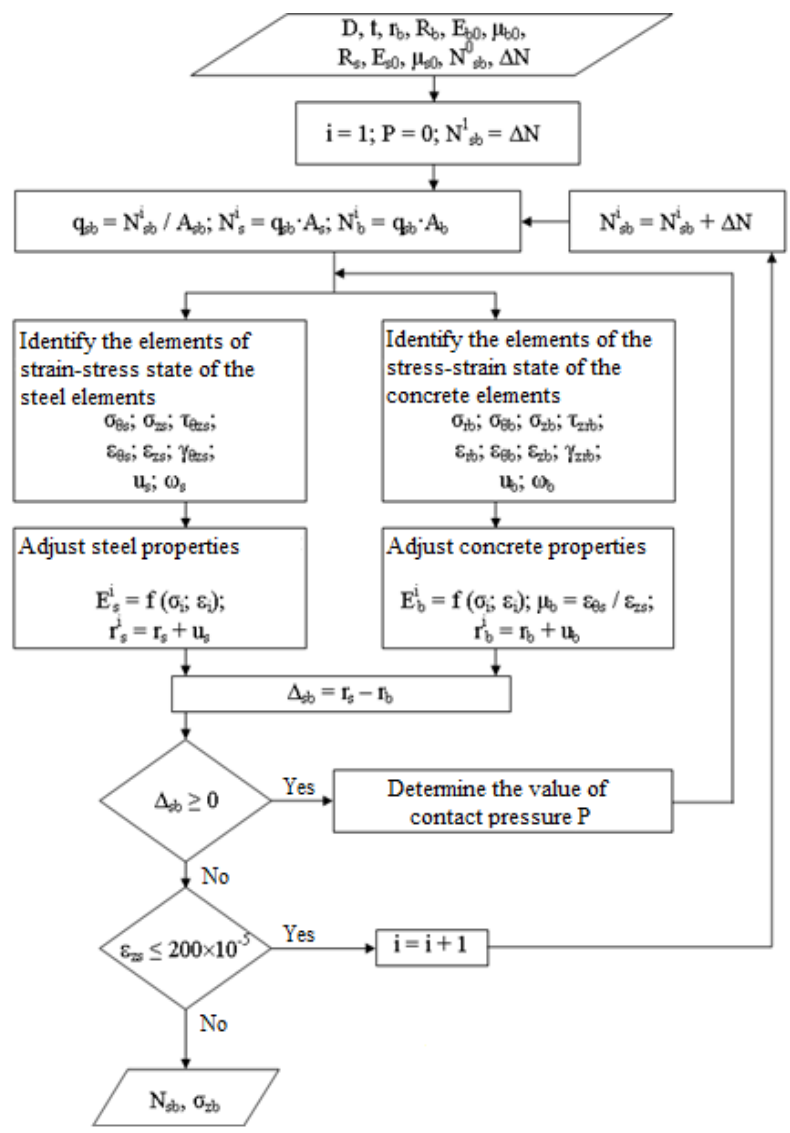

Fig. 4. Block diagram of the calculation algorithm of tube confined concrete elements with strengthened cores.

In addition, we consider it necessary to mention that several factors given in this paper have been taken into account in order to construct a method for evaluating the stress-strain state of a steel tube [8]. They are the following: the calculation of tube confined concrete is performed by an iterative method with changing the parameters of elasticity; within a separate stage of calculation, the work of the steel tube is considered elastic; we consider the stress-strain state of a tube as the sum of states at simple loads. So as simple loads we accept: longitudinal compression; uniform internal compression; uniform external compression. To do this, we use known results from [12].

\subsection{Testing of methodology}

During the experiments, the following series of samples were tested:

\begin{tabular}{c|c|c|c}
$\begin{array}{c}\text { Samples } \\
\text { series }\end{array}$ & $\begin{array}{c}\text { Tube external } \\
\text { diameter, D, } \\
\text { [mm] }\end{array}$ & $\begin{array}{c}\text { Tube wall } \\
\text { thickness } \\
\text { t, [mm] }\end{array}$ & $\begin{array}{c}\text { Concrete } \\
\text { strength, } \\
\text { fck.prism, [MPa] }\end{array}$ \\
\hline T-I-1 & 110,6 & 2,75 & - \\
T-I-2 & 163,0 & 5,50 & - \\
T-I-3 & 204,4 & 5,20 & - \\
& & & \\
T-I-11 & 110,6 & 2,75 & 50,0 \\
TC-I-12 & 110,6 & 2,75 & 64,2 \\
TC-I-13 & 110,6 & 2,75 & 80,0
\end{tabular}




\begin{tabular}{c|c|c|c}
$\begin{array}{c}\text { Samples } \\
\text { series }\end{array}$ & $\begin{array}{c}\text { Tube external } \\
\text { diameter, D, } \\
{[\mathbf{m m}]}\end{array}$ & $\begin{array}{c}\text { Tube wall } \\
\text { thickness } \\
\text { t, [mm] }\end{array}$ & $\begin{array}{c}\text { Concrete } \\
\text { strength, } \\
\text { fck.prism, [MPa] }\end{array}$ \\
\hline TC-I-21 & 163,0 & 5,50 & 50,0 \\
TC-I-22 & 163,0 & 5,50 & 64,2 \\
TC-I-23 & 163,0 & 5,50 & 80,0 \\
& & & \\
TC-I-31 & 204,4 & 5,20 & 50,0 \\
TC-I-32 & 204,4 & 5,20 & 54,2 \\
TC-I-33 & 204,4 & 5,20 & 80,0
\end{tabular}

Experimental investigations of tube confined concrete elements with high-strength concrete cores have proven that, by the time of the appearance of fluidity in the shell, the latter with concrete core work in parallel. Therefore, when developing a method for evaluating the stress-strain state of such structures, we believe that the tube-shell and the concrete core work in parallel until the fluidity of the tube shell begins (Fig. 5). At a later stage, the concrete core and the shell work together.
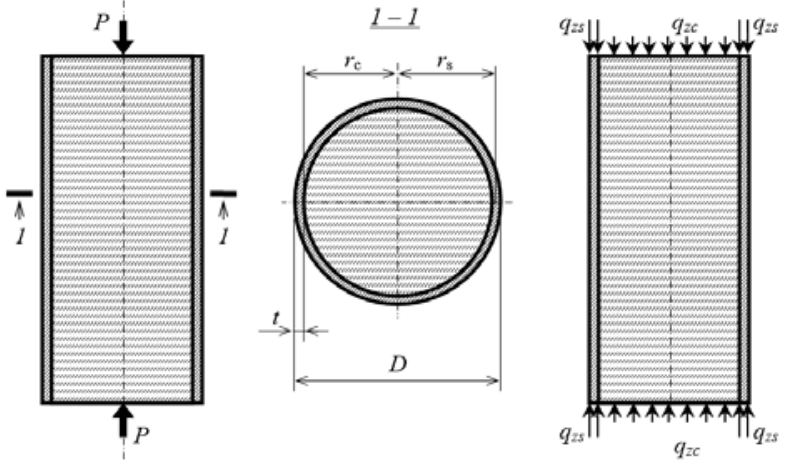

Fig. 5. Design diagram of tube confined concrete element with high-strength concrete core.

The peculiarity of the deformation of the studied samples is the symmetry about the central axis. For convenience, the stress-strain state is described using cylindrical coordinates. In this case, the components of the stress-strain state are not dependent on the angle $\theta$ (Fig. 6) [8].
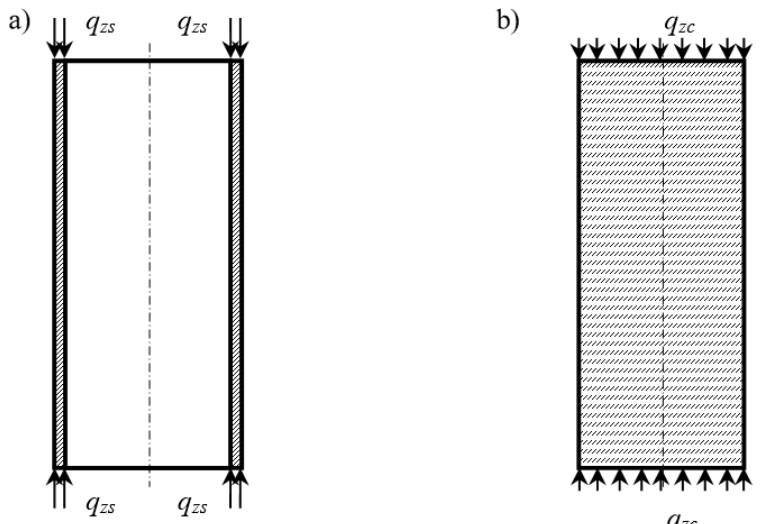

$q_{z c}$

Fig. 6. Design diagram of tube shell (a) and high-strength concrete core (b).

Using the above calculation method, the carrying capacity of centrally compressed concrete elements with strengthened cores was calculated. The boundary condition is the moment of transition of the outer shell material from the elastic to the elastic-plastic stage of operation. The results of comparing the experimental results of the carrying capacity with the theoretical data are shown in Table 1.

Table 1. Comparison of theoretical and experimental data.

\begin{tabular}{|c|c|c|c|}
\hline \multirow{2}{*}{ Sample series } & \multicolumn{3}{|c|}{ Carrying capacity, [kN] } \\
\cline { 2 - 4 } & experimental & theoretical & difference, $\%$ \\
\hline TC-I-11 & 652 & 567 & -13 \\
\hline TC- $\boldsymbol{I}-12$ & 716 & 652 & -9 \\
\hline TC-I-13 & 869 & 834 & -4 \\
\hline TC-I-21 & 1840 & 1693 & -8 \\
\hline TC- $\boldsymbol{I}-22$ & 2100 & 2016 & -6 \\
\hline TC-I-23 & 2400 & 2160 & -6 \\
\hline TC- $\boldsymbol{I}-31$ & 2970 & 2584 & -10 \\
\hline TC-I-32 & 3386 & 3251 & -11 \\
\hline TC- $\boldsymbol{I}-33$ & 3636 & 3163 & -12 \\
\hline
\end{tabular}

The rational use of tube confined concrete can also be judged by the efficiency coefficients $[4,5,7]$. The first of them characterizes the efficiency of the tube concrete element work as a whole $\left(m_{b, c f}\right)$, the second coefficient takes into account the efficiency of concrete work in the tube confined concrete element $\left(\eta_{b, c f}\right)$. Also in the research of this subject we use the coefficient $n$, which characterizes the relationship between the forces $N_{l}$, when the sample reaches the limit state of the bearing capacity when reaching the yield strength in the shell to the complete destruction of the sample $N_{2}$

Table 2 compares the results of determining the coefficient of the concrete work efficiency in tube confined concrete elements with strengthened cores.

Table 2. Comparison of theoretical and experimental data of the coefficient $\boldsymbol{\eta}$ values.

\begin{tabular}{|c|c|c|c|}
\hline \multirow{2}{*}{ Sample series } & \multicolumn{3}{|c|}{ Efficiency coefficient $\boldsymbol{\eta}$} \\
\cline { 2 - 4 } & experimental & theoretical & difference, $\%$ \\
\hline TC- $\boldsymbol{I}-11$ & 4,13 & 3,22 & $-28,3$ \\
\hline TC- $\boldsymbol{I}-12$ & 4,11 & 3,56 & $-15,4$ \\
\hline TC- $\boldsymbol{I}-13$ & 3,69 & 3,31 & $-11,5$ \\
\hline TC- $\boldsymbol{I}-21$ & 1,75 & 1,66 & $-5,4$ \\
\hline TC- $\boldsymbol{I}-22$ & 1,60 & 1,54 & $-3,9$ \\
\hline TC- $\boldsymbol{I}-23$ & 1,51 & 1,59 & $+5,0$ \\
\hline TC- $\boldsymbol{I}-31$ & 1,49 & 1,23 & $-21,1$ \\
\hline TC-I-32 & 1,42 & 1,42 & 0,0 \\
\hline TC- $\boldsymbol{I}-33$ & 1,41 & 1,34 & $-5,2$ \\
\hline
\end{tabular}

\section{Conclusion}

An analytical method for determining the carrying capacity of tube confined concrete elements with strengthened cores by establishing the stress-strain state of separate cross-sectional elements has been developed. This approach allows us to establish the effectiveness of using concrete of different classes as a core. And also it is possible to evaluate the effectiveness of structural tube confined concrete element with strengthened cores compared to steel elements. The proposed methods for determining the carrying capacity and performance of concrete in tube confined concrete elements with strengthened cores ensure satisfactory coincidence of theoretical and experimental data. 


\section{References}

[1] C.S. Huang, Y.-K. Yeh, G.-Y. Lie, H.-T. Hu, K.C. Nsai, Y.T. Weng, S.H. Wang, M.-H Wu, J. Struct. Eng. 9, 1222-1230 (2002)

[2] A. Kuranovas, A.K. Kvedaras, J. Civ. Eng. and Manag. 13 (2), 131-141 (2007)

[3] Zhi-wu Yu, Fa-xing Ding, C.S. Cai, J. Constr. Steel Res. 63, 165-174 (2007)

[4] L.I. Storozhenko (ed.), Stalezalizobeton (Steel reinforced concrete) (PolNTU, Poltava, 2006)

[5] L.I. Storozhenko, D.A. Yermolenko, O.I. Lapenko, Trubobeton (Tube confined concrete) (Poltava, 2009)

[6] I.N. Mohilevtseva, O.V. Razumova, Tube confined concrete frame - a rational choice when designing high-rise buildings. https://elima.ru/articles/?id=166 (2012). Accessed 20 Sep 2020

[7] V.I. Yefimenko, A.P. Sukhan, Build. Constr. 70, 96102 (2008)

[8] O.A. Palyvoda, O.I. Lapenko, Study of joint work of shell and core of tube confined concrete elements with strengthened core, Trans Tech Publ. Ltd, Switzerland, 968, 258-266 (2019)

[9] V.I. Yefimenko, Steel load carrying structures filled with spun concrete, Dissertation, 2009

[10]A.A. Iliushin, Plasticity (Gortekhizdat, Moscow, 1948)

[11]D.V. Vainberg, Planks, disks, beam-walls (Gosstroyizdat, Kyiv, 1959)

[12] K.V. Solianik-Krassa, Axisymmetric problem of the theory of elasticity (Gosstroyizdat, Moscow, 1987) 